\title{
Surface Modifications on Aesthetically Restored Teeth following Home Bleaching with $16 \%$ Peroxide Carbamide
}

\author{
Augusto Bodanezi ${ }^{\mathrm{a}}$ \\ Marcos Eugênio de Bittencourt ${ }^{b}$ \\ Rafaela Vanni Bodanezic \\ Tatiana Zottis ${ }^{c}$ \\ Etiene Andrade Munhoz ${ }^{\mathrm{d}}$ \\ Bruno Carlini-Júnior ${ }^{b}$
}

\section{ABSTRACT}

Objectives: This clinical study evaluated the effects of a highly concentrated home-bleaching agent on the surface morphology of aesthetically restored teeth.

Methods: Specimens of human enamel and micro-hybrid composite resin were randomly adhered to the buccal side of right premolar and molar teeth of ten volunteers, who underwent a routine home-bleaching procedure with $16 \%$ carbamide peroxide on the upper jaw for 8 days. The mandibular unbleached specimens served as paired controls $(n=10)$. Ultra-structural assessment of the sample was carried out by scanning electron microscopy, and the resulting images were blindly evaluated for topographical alterations. The differences between groups were calculated with the Mann-Whitney test adjusted at the $95 \%$ confidence interval.

Results: The bleached enamel presented significantly more morphological changes than the control group. The aspect of resin composite exposed to the whitening substance was statistically similar to that observed in the corresponding control group $(P<.05)$.

Conclusions: The occurrence of surface topography changes during home bleaching of aesthetically restored teeth with 16\% carbamide peroxide was restricted to enamel. (Eur J Dent 2011;5:157162)

Key words: Tooth bleaching; Carbamide peroxide; Composite resin; Tooth enamel.

- a Department of Dentistry, Endodontics and Dental Materials, School of Dentistry, University of São Paulo, Bauru, SP, Brazil.

b Department of Restorative Dentistry, School of Dentistry, University of Passo Fundo, Passo Fundo, RS, Brazil.

Department of Restorative Dentistry, School of Dentistry, University of Passo Fundo, Passo Fundo, RS, Brazil.

d Department of Conservative Dentistry, School of Dentistry, Federal University of Rio Grande do Sul, Porto Alegre, RS, Brazil.
- Corresponding author: Dr. Augusto Bodanezi School of Dentistry, Department of Dentistry, Endodontics and Dental Materials University of São Paulo 17012-90 Al. Octávio Pinheiro Brizolla 9-75, Bauru, Brazil Phone: +55 1432358344 Fax: +55 1432358345 E-mail:abodađusp.br 


\section{INTRODUCTION}

Home bleaching is a popular and convenient treatment to improve the appearance of vital teeth. ${ }^{1}$ During this procedure, whitening gel is deposited on moulded acrylic trays that allow the solution to act indistinctly over both enamel and pre-existing aesthetic restorations. Many investigations have shown that low-concentration bleaching substances may damage these structures $^{1-3}$ and thus increase their susceptibility to staining and bacterial adhesion. ${ }^{4-6}$

Major colour improvements are sometimes enthusiastically desired by patients, whereas the adverse effects of whitening procedures may be unintentionally downplayed by professionals. Recently, manufacturers released a flood of highconcentration bleaching gels in the market. These gels are claimed to increase the effectiveness as well as longevity of at-home treatments. As expected, initial in vitro studies reported significant alterations to enamel ${ }^{7,8}$ or composite resins. ${ }^{2,9}$ However, these results were not confirmed by the scant evidence originating from clinical investigations. ${ }^{10,11}$

Since the effects of whitening substances have been evaluated separately and in a great diversity of regimens, it is difficult to extend those incompatible evidences to aesthetically restored teeth. Thus, this prospective clinical study aimed to assess simultaneously the effects of $16 \%$ carbamide peroxide on the external topography of enamel and composite resin.

\section{MATERIALS AND METHODS}

Preparation of specimens

This study was initiated only after obtaining suitable approval from the Local Ethics Committee, which is in conformity with the Declaration of Helsinki (DoH). A total of five human impacted upper third molars were included in this study. All molars included fit the following criteria: 1) arising from different donors and 2) without structural damage, signs of hypomineralisation (white spots) or prior contact with saliva. After cleaning, teeth were individually positioned in a sectioning machine equipped with a water-cooled $300-\mu \mathrm{m}$ thick diamond saw (Minitorm, Struers A/S, Copenhagen, Denmark). Roots were removed at the cemento-enamel junction. After that, the remain- ing crows were equidistantly sectioned in the mesiodistal and buccolingual directions to provide four enamel fragments $(4 \mathrm{~mm} \times 4 \mathrm{~mm}$ and $2 \mathrm{~mm}$ thickness) each.

The pieces obtained were moulded into a light regular-set silicon (Virtual Light-Body, Ivoclair Vivadent, São Paulo, SP, Brazill, and the moulds were filled with increments of a micro-hybrid composite resin (EA2 Opallis, FGM Dentscare Ltda, Joinville, SC, Brazill. Moulds were sequentially polymerised over 20 seconds using a lightemitting diode unit set between 460 and $480 \mathrm{~mW} /$ $\mathrm{cm}^{2}$ (Ultra-Blue i5, DMC Vasconcellos, São Carlos, SP, Brazil) in order to produce enamel-like composite resin specimens.

The resulting 40 specimens (20 of composite resin) were then individually placed at the end of polyvinyl chloride cylinders $3 / 4$ inch diameter and $20 \mathrm{~mm}$ high), which were filled with chemicallyactivated acrylic resin (Technovit 4000, Heraeus Kulzer, Wehrheim, Germanyl. After 24 hours, the exposed side of each embedded fragment was flattened and polished by sequential use of wet 400-, 600- and 1200-grit silicon carbide pa-

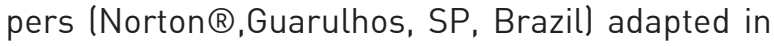
a slow-speed polishing machine set at $150 \mathrm{rpm}$ (Ballerup, Struers A/S, Copenhagen, Denmark). The finished specimens were then removed from blocks and ultrasonically cleaned for 5 minutes before being sterilised and stored in distilled water $\left(37 \pm 0.5^{\circ} \mathrm{C}\right)$ until use.

Ten volunteers ( $20-25$ years old) were recruited to participate in this investigation. All volunteers presented the following inclusion criteria: absence of caries and gingivitis, no history of xerostomia, no previous bleaching therapy and willingness to understand and sign a consent form. Participants had their maxillary right teeth cleaned with a rotary toothbrush and dentifrice before isolation with a rubber dam and stainless steel clamps. The buccal sides of the right upper second premolar and first molar were etched with $37 \%$ phosphoric acid (Dentsply, Petrópolis, RJ, Brazil) for 30 seconds and immediately washed with running water for 60 seconds. To fix the enamel and composite resin randomly on these surfaces, a two-step adhesive (Adper ${ }^{\mathrm{TM}}$ Scotchbond, 3M, Sumaré, SP, Brazil) was brushed and light-polymerised for 15 seconds before an increment of low-viscosity composite resin (Natural Flow, DFL, Jacarepagua, RJ, Brazil) was 
used to glue the specimens on teeth using lightpolymerisation for 40 seconds.

These same procedures were performed on the adjacent lower right teeth to fix the enamel and composite resin on specimens not undergoing the bleaching process. These specimens thus served as paired controls $(n=10)$.

\section{Bleaching process}

An upper jaw impression was taken of each participant with alginate materials (Jeltrate, Dentsply, Petrópolis, RJ, Brazil), and impressions were poured with type II dental stone (Pasom, São Paulo, $\mathrm{SP}$, Brazil) to fabricate a master cast. A $0.5 \mathrm{~mm}$ thick wax layer was applied on the buccal face of each cast $1.5 \mathrm{~mm}$ away from the gingival margin to fabricate reservoirs for the bleaching gel. Soft trays (Cristal, Bio-art, São Carlos, SP, Brazil) were made using a heat/vacuum tray-forming machine (Plasvac P7, Bio-art, São Carlos, SP, Brazil). The trays were tested and trimmed to fit the gingival margin of each volunteer.

The participants were instructed to use the tray at the upper arch and to keep the bleaching product (Whiteness Perfect 16\%, FGM Dentscare Ltda, Joinville, SC, Brazil) in contact with teeth exactly 6 hours per day for 8 consecutive days. No restrictions on dietary or hygiene habits were imposed, but the necessity to remove the residual solution after each whitening session was emphasised. Every 48 hours, the volunteers were questioned about sensitivity of teeth or soft tissue. When hypersensitivity was confirmed, desensitising treatment was performed with $2 \%$ potassium nitrate (Desensibilize KF 2\%, FGM Dentscare Ltda, Joinville, SC, Brazil). The four subjects were instructed to place the desensitizing gel in their tray and wear it for 20 minutes once a day, as recommended by the manufacturer.

\section{Surface analysis}

After detachment from teeth, the specimens were left to dehydrate for 96 hours before being gold sputter-coated to permit analysis in a scanning electron microscope (DSM-940 A, Carl Zeiss, Oberkochen, Germanyl. Digital SEM photomicrographs were taken at four different areas over the surface of each fragment at 5000x magnification. Enamel and resin surface alterations were classified qualitatively by increasing order of scores rang- ing from 0 (no observable alterations) to 4 (heavy erosion with deep depressions). Prior to blind analysis of the 160 images, a single examiner was calibrated by viewing 30 additional SEM micrographs. A second assessment was repeated 4 weeks after the first evaluation, and the data obtained were considered as a whole for statistical comparison.

\section{Statistical analysis}

Statistical differences between the experimental and appropriate control groups were executed with the Mann-Whitney Test adjusted to the $95 \%$ confidence interval. The intra-observer agreement was determined using Cohen's Kappa statistic. Statistical analyses were performed with SPSS software v.11.0 for Windows (SPSS Inc., Chicago, IL, USA).

\section{RESULTS}

Representative SEM images are shown in Figures 1-4, and the results of the Mann-Whitney test are presented in Table 1.

Following application of $16 \%$ carbamide peroxide, the enamel surface in the experimental group exhibited extensive mild erosion with shallow depressions and destruction of interprismatic matrix. This appearance differed significantly from that of non-bleached enamel fragments, which exhibited a smooth and amorphous aspect.

The bleached composite resin specimens displayed a flat appearance, with slight erosion and some striation due to the grinding procedure. This appearance was statistically similar to that observed in the control group $(\mathrm{P}<$.05). Intra-observer agreement was 0.89 .

\section{DISCUSSION}

This study was the first to adhere human enamel and resin fragments to the buccal side of regular teeth to reproduce, as closely as possible, an actual home-bleaching situation. This manoeuvre permitted controlled and continuous exposure of specimens to saliva, beverages and oral hygiene habits, a procedure completely different from prior investigations in which removable appliances were adopted to carry the specimens. ${ }^{1,9-11}$ Therefore, such biases make previous studies difficult to interpret and compare.

Scanning electron microscopy is a simple and effective method for identifying surface morphology alterations on enamel and composite resins 
submitted to home bleaching. 1,12,13 Nonetheless, dehydration and metal coating necessary to SEM analysis are able to change part of the specimens structure; ${ }^{14}$ thus, the appearance of enamel observed may not correspond precisely to that of bleached enamel in its natural condition.

Porosity and erosion resulting from demineralisation were demonstrated by SEM after in vitro

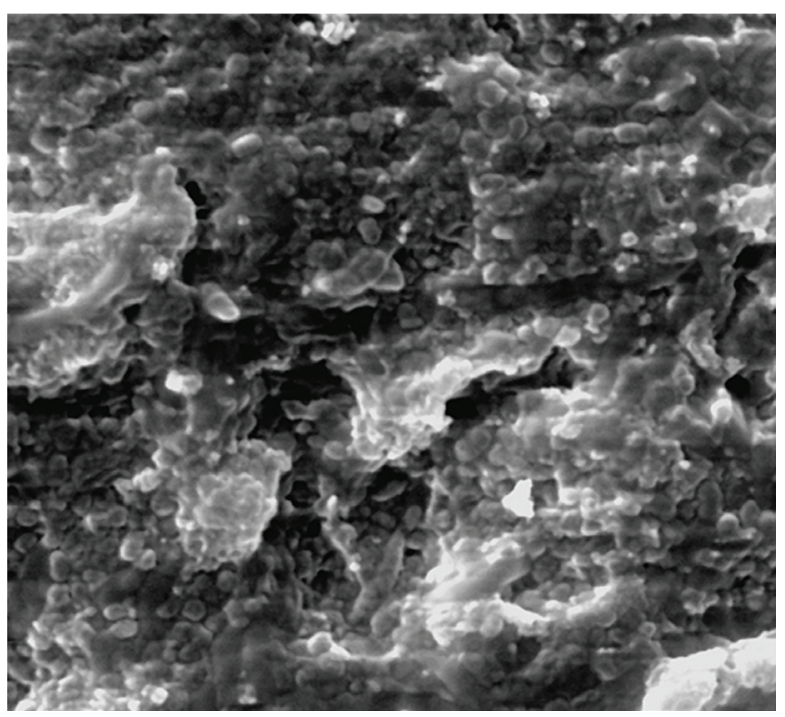

Figure 1. Representative SEM micrograph of bleached enamel at original magnification 5000x.

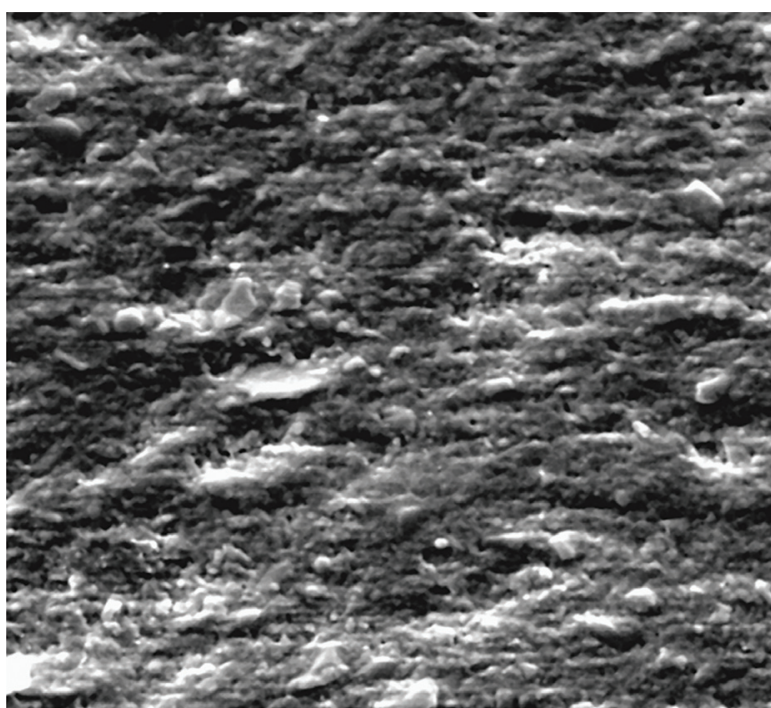

Figure 3. Representative SEM micrograph of bleached resin composite at original magnification 5000x and in vivo intermittent exposure of enamel to $10 \%$ carbamide peroxide. 1,15,16 In the present study, the time of contact between the enamel and whitening gel (48 hours in total) was shorter than those adopted in other investigations $\mathrm{s}^{7,10,15-17}$ and sufficient to produce an eroded appearance similar to that of acid-etched surfaces. This finding has already been observed in vitro by Adebayo et $\mathrm{al}^{8}$ but not in

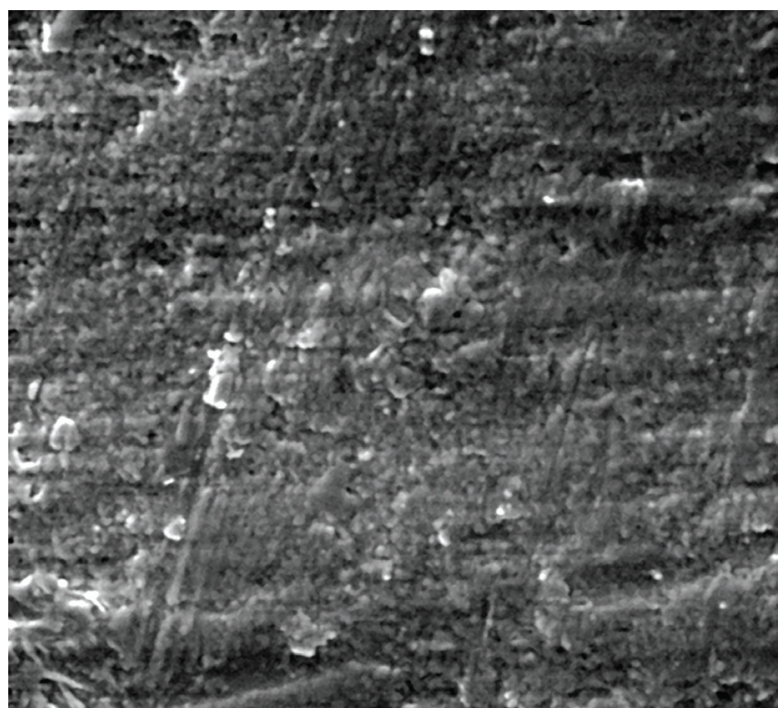

Figure 2. Representative SEM micrograph of unbleached enamel at original magnification 5000x.

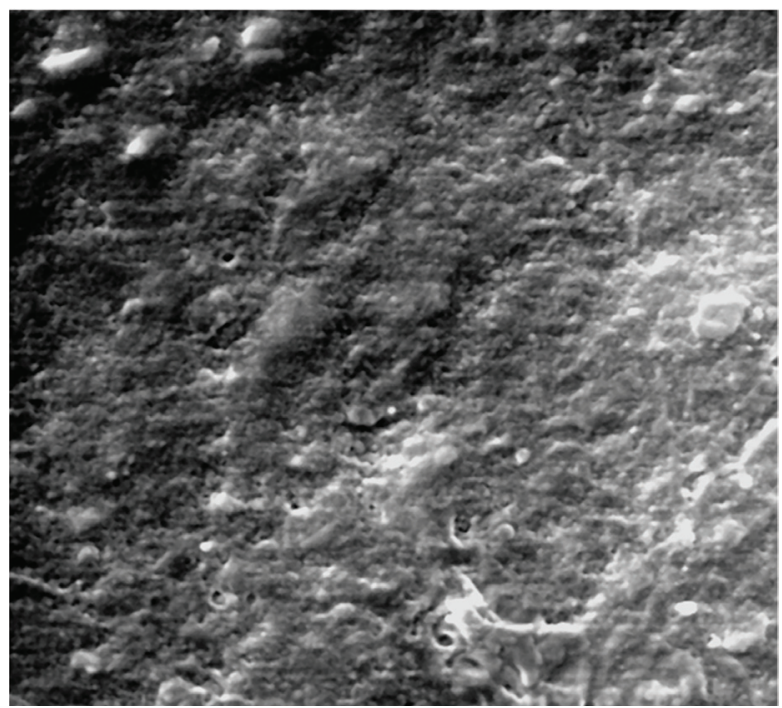

Figure 4. Representative SEM micrograph of unbleached resin composite at original magnification 5000x.

Table 1. Median values and ranges of scores attributed to enamel and resin composite micrographs ( ${ }^{*}$ statistically significant).

\begin{tabular}{|c|c|c|c|}
\hline Substrate & Treatment & Median & $P$ value \\
\hline \multirow{2}{*}{ Enamel } & bleached & $3.4(3.0-4.0)$ & $0.004^{*}$ \\
\hline & unbleached & $1.4(1.0-2.0)$ & $0.004^{*}$ \\
\hline \multirow{2}{*}{ Composite resin } & bleached & $2.3(1.0-3.0)$ & 0.091 \\
\hline & unbleached & $1.6(1.0-2.0)$ & 0.091 \\
\hline
\end{tabular}

European Journal of Dentistry 
vivo by Metz et al, ${ }^{11}$ likely because the enamel specimens used in the latter research had prior contact with fluoride.

The damage detected on enamel could be justified by the ability of urea, derived from the reaction of carbamide peroxide with water, to denature protein structures and thus cause structural and morphological changes through the degradation of organic molecules. ${ }^{14}$ In addition, the slightly acidic $\mathrm{pH}$ of the gel tested $(6.04)^{18}$ may have contributed secondarily to these external modifications. ${ }^{12,17}$ However, a possible increased susceptibility of unerupted third molars' enamel to the action of chemical agents such as carbamide peroxide should be considered before this result can be generalized.

Since these findings were detected in vivo, it may be suggested that the expected dissolving and buffering effects of saliva on the whitening gel ${ }^{19}$ or the attenuation provided for a peroxide-consuming enzyme on the surface of teeth ${ }^{20}$ were not able to minimise the deleterious impact of a highly concentrated bleaching gel on human enamel. Alterations to enamel topography caused by low concentrations of bleaching gels may undergo repair over time by precipitation of mineral phases derived from saliva into the existing porosities. 1,16,21 Tooth remineralisation is a slow process, and the high concentration of bleaching gel used in this study probably smothered the saliva recovery properties. Clinically, however, erosion reversal should be expected as soon as whitening gel application is discontinued. In recent laboratory investigations, the addition of fluoride to carbamide peroxide gel resulted in less demineralisation and shorter periods for enamel hardening recovery following bleaching. ${ }^{22,23}$

The absence of significant alterations on the surface of the composite resin bleached was already described for nano-hybrid and packable resins after extended periods of in situ and in vitro exposure to $15 \%$ carbamide peroxide.6,11 Since morphological alterations were noticed on enamel specimens subjected to the same home-whitening conditions, we inferred that salivary attenuation of the highly concentrated peroxide carbamide substance did not completely respond for resin resistance to bleaching detrimental effects. ${ }^{19,20}$ Enamel and composite are completely different materials, and an incompatibility between the solvents present in the whitening substances and the components in the polymer matrix of the resin-based material may justify the absence of deleterious effects on resin surfaces. 2,11,13,24

Another possible explanation for the absence of statistical difference between groups relates to the subjective and qualitative evaluations necessary for the SEM micrographs and also to the low number of composite resin specimens used; it is possible that major changes in the surface of bleached resin have been underrated, despite the effort to calibrate the examiners, thus reducing the numerical difference between groups. Although not widespread as SEM, atomic force microscopy (AFM) enables quantitative and independent measurement of specimens' surface morphology in their natural condition. ${ }^{17}$ Thus, the possibility of getting different results, if AFM had been used, cannot be disregarded.

Colour improvements have been described separately for enamel ${ }^{25}$ and composite resin. ${ }^{26}$ Since these structures were bleached together in this investigation, we provide evidence that these substrates responded differently to $16 \%$ carbamide peroxide. This phenomenon may justify the common observation of poor colour matching of pre-existing restorations after home whitening. ${ }^{11}$ Nonetheless, given the diversity of composite resins available, the susceptibility of their surfaces to this or other vital bleaching regimens and formulations may be different.

To date, it is uncertain how the surface changes that occur during bleaching are related to colour improvement and/or increases in staining susceptibility. 5,6 However, the complete repolishing of aesthetically restored teeth to recover smoothness and delay staining of composite resins ${ }^{9,27}$ may both be unnecessary, at least for the material studied, and thus avoid the irreversible loss of enamel structure.

\section{CONCLUSIONS}

Within the limitations of this clinical study, we concluded that the occurrence of surface topography changes during home bleaching of aesthetically restored teeth with $16 \%$ carbamide peroxide was restricted to enamel.

\section{ACKNOWLEDGMENTS}

Dr. Elliot Watanabe Kitajima, from the Nucleus of Research Support, Electron Microscopy Center (NAP/MEPA-ESALQ/USP). We also thank all colleagues and volunteers who contributed to this research. 


\section{REFERENCES}

1. Shannon H, Spencer P, Gross K, Tira D. Characterization of enamel exposed to $10 \%$ carbamide peroxide bleaching agents. Quintessence Int 1993;24:39-44.

2. Turker SB, Biskin T. Effect of three bleaching agents on the surface properties of three different esthetic restorative materials. J Prosthet Dent 2003;89:466-473.

3. Yalcin F, Gurgan S. Effect of two different bleaching regimens on the gloss of tooth-colored restorative materials. Dent Mater 2005;21:464-468.

4. Hosoya N, Honda K, Lino F, Arai T. Changes in enamel surface roughness and adhesion of Streptococcus mutans to enamel after vital bleaching. J Dent 2003;31:543-548.

5. Ghavamnasiri M, Bidar M, Rad AH, Namazikhah MS. The effect of 16 percent carbamide peroxide on enamel staining susceptibility. J Calif Dent Assoc 2006;34:873-876.

6. Yu H, Pan X, Lin Y, Li Q, Hussain M, Wang Y. Effects of carbamide peroxide on the staining susceptibility of tooth-colored restorative materials. Oper Dent 2009;34:72-82.

7. Basting RT, Rogrighes Jr AL, Serra MC. The effects of seven carbamide peroxide bleaching agents on enamel microhardness over time. J Am Dent Assoc 2003;134:1335-1342.

8. Adebayo OA, Burrow MF, Tyas MJ. An SEM evaluation of conditioned and bonded enamel following carbamide peroxide bleaching and casein phosphopeptide-amorphous calcium phosphate (CPP-ACP) treatment. $J$ Dent 2009;37:297-306

9. Lima DA, De Alexandre RS, Martins AC, Aguiar FH, Ambrosano GM, Lovadino JR. Effect of curing lights and bleaching agents on physical properties of a hybrid composite resin. J Esthet Restor Dent 2008;20:266-273.

10. Metz MJ, Cochran MA, Matis BA, Gonzales C, Platt JA, Pund MR. Clinical evaluation of $15 \%$ carbamide peroxide on the surface microhardness and shear bond strength of human enamel. Oper Dent 2007; 32:427-436.

11. Li Q, Yu H, Wang Y. Color and surface analysis of carbamide peroxide bleaching effects on the dental restorative materials in situ. J Dent 2009;37:348-356.

12. McGuckin RS, Babin JF, Meyer BJ. Alterations in human enamel surface morphology following vital bleaching. $J$ Prosthet Dent 1992;68:754-760.

13. Langsten RE, Dunn WJ, Hartup GR, Murchison DF. Higher-concentration carbamide peroxide effects on surface roughness of composites. J Esthet Restor Dent 2002;14:9296.

14. Hegedus C, Bistey T, Flora-Nagy E, Keszthelyi G, Jenei A. An atomic force microscopy study on the effect of bleaching agents on enamel surface. J Dent 1999;27:509-515.
15. Josey AL, Meyers IA, Romaniuk K, Symons AL. The effect of a vital bleaching technique on enamel surface morphology and the bonding of composite resin to enamel. $J$ Oral Rehabil 1996;23:244-250.

16. Türkün M, Sevgican F, Pehlivan Y, Aktener BO. Effects of $10 \%$ carbamide peroxide on the enamel surface morphology: a scanning electron microscopy study. $J$ Esthet Restor Dent 2002;14:238-244.

17. Zalkind M, Arwaz JR, Goldman A, Rotstein I. Surface morphology changes in human enamel, dentin and cementum following bleaching: a scanning electron microscopy study. Endod Dent Traumatol 1996;12:82-88.

18. Ribeiro JCR, Moysés MR, Dias SC, Gomes PN, Reis AC, Ribeiro JGR. Evaluation of tooth bleaching products' $\mathrm{pH}$. Dent Archiv 2006;42:33-39.

19. Hannig C, Zech R, Henze E, Dreier S, Attin T. Peroxide release into saliva from five different home bleaching systems in vivo. Am J Dent 2005;18:13-18.

20. Matis BA, Gaiao U, Blackman D, Schultz FA, Eckert GJ. In vivo degradation of bleaching gel used in whitening teeth. $J$ Am Dent Assoc 1999;130:227-235.

21. Flaitz CM, Hicks MJ. Effects of carbamide peroxide whitening agents on enamel surfaces and caries-like lesion formation: an SEM and polarized light microscopic in vitro study. J Dent Child 1996;63:249-256.

22. Attin T, Betke H, Schippan F, Wiegand A. Potential of fluoridated carbamide peroxide gels to support post-bleaching enamel re-hardening. J Dent 2007;35:755-759.

23. Chen H, Chang C, Liu J, Chuang S, Yang J. Effect of fluoride containing bleaching agents on enamel surface properties. J Dent 2008;36:718-725.

24. Bailey SJ, Swift Jr EJ. Effects of home bleaching products on composite resins. Quintessence Int 1992;23:489-494.

25. Braun A, Jepsen S, Krause F. Spectrophotometric and visual evaluation of vital tooth bleaching employing different carbamide peroxide concentrations. Dent Mater 2007;23:165-169.

26. Villalta P, Lu H, Okte Z, Garcia-Godoy F, Powers JM. Effects of staining and bleaching on color change of dental composite resins. J Prosthet Dent 2006;95:137-142.

27. Wattanapayungkul $P$, Yap AU. Effects of in-office bleaching products on surface finish of tooth-colored restorations. Oper Dent 2003;28:15-19. 